MATEC Web of Conferences 53, 01065 (2016)

DOI: $10.1051 /$ matecconf/20165301065

(C) Owned by the authors, published by EDP Sciences, 2016

\title{
Experimental studies of Steel Corrugated Constructions
}

\author{
Yuriy Lazarev ${ }^{1,}$, Alisher Akhatuly ${ }^{1, a}$, Raushan Alzhanova ${ }^{1,}$ and Alla Panfilova ${ }^{1}$ \\ ${ }^{1}$ Peter the Great Saint-Petersburg Polytechnic University, 29 Polytechnicheskaya st., St.Petersburg, 195251, \\ Russian Federation
}

\begin{abstract}
The purpose of this particular article is to assess existing calculations of steel corrugated constructions. Steel Corrugated Construction is a perspective type of constructions, which is exhibiting numerous advantages in comparison with one that currently applied in automobile and railroad networks (reinforced concrete water-throughput pipes, reinforced concrete frame bridges). The evaluation of experimental data on models of constructions of this particular type has been carried out in order to improve calculations of Steel Corrugated Constructions.
\end{abstract}

\section{Introduction}

A considerable share in road construction is occupied by small artificial constructions - waterthroughput pipes and small bridges. In the last decade, there was an extensive circulation of steel corrugated pipes (SCP), construction of which has significantly reduced labor input and material capacity in contrast with reinforced concrete pipes, which in its turn lead to cost reductions in construction.

Nowadays there is a large number of the programs allowing solving numerally equations of mathematical physics with a method of finite elements. There are special programs solving a narrow class of tasks: calculation of construction designs, calculation of problems of mechanics of soil, hydrodynamics. In addition, there are universal programs allowing modeling any systems and the phenomena, but demanding high qualification of the researcher. Whether universal or special, there are programs not only commercial but also free of charge, which are just as efficient and functional [1, $2,5]$.

It is possible to claim that currently modeling virtually of any system is available to an engineer, including filling constructions from corrugated steel considering all aspects of work. However, for a number of reasons practical application of programs that are solving the equations of mathematical physics for calculation of corrugated steel constructions is rather complicated.

Formulas for calculation are borrowed from VSN 176-78, nevertheless it is necessary to expand a scope of formulas from the appendix 11 for calculation of a design for limit balance. The coefficient of increasing of bearing capacity $K$ has to be modified by means of a technique stated in chapter III of the book "Steel Corrugated Pipes under Embankments" (authors of Bells N.M., Yankovsky O. A., Shcherbina K.B., Chernyakhovsk S.E Transport) and section VI.3 of the book "Water-Throughput Pipes under Embankments", considering all contemporary nomenclature of corrugations and of steel.

${ }^{a}$ Corresponding author: akhatuly_alisher@mail.ru 
Calculated bearing capacity of a pipe out of $\mathrm{q}_{1}$ soil, has to be specified, bearing in mind actual durability of applied steel $[9,18,22]$.

Linear calculation of corrugated constructions via method of finite elements is acceptable to be executed in any modern calculated complex. Therefore, it is unnecessary to be limited to purely linear calculation. High flexibility of a corrugated construction permits it to work beyond elasticity limit, which is potential to be carried out in programs of linear calculation due to the elementary iterative procedure. The latter formed the basis of obtaining a formula that allows determining of bearing capacity recommended by VSN (The instruction on design and construction of steel corrugated waterthroughput pipes). According to standards, it is necessary to consider two ways of modeling the soil surrounding the construction: linearly - deformable environment and elastic connections. For the first approach, it is necessary to make recommendations for assigning the sizes of soil mass model, the module of elasticity and Poisson's coefficient. For the second approach, it is necessary to provide a technique of determination of rigidity of connections and an order of their deactivation while carrying out iterative procedure $[13,17,9]$.

Nonlinear calculation via method of finite elements is based on application of reliable models of functioning of the pipe material and the soil surrounding it considering all stages of work. It is essential to specify in standards and accurately to describe the recommended models of soil and material of corrugation, and of an area of their application. Parameters of any suggested model have to be attached to real parameters of the applied soil and steel, which is checked and provided in the course of construction $[29,32]$.

Other problem capable to nullify all efforts of scientists and designers on creation of calculated and theoretical basis is inadequate quality of work constructing a corrugated pipe.

Small artificial constructions (water-throughput pipes, cattle crossing, etc.) make the main part of a number of bridge constructions built on automobile and railroad networks. There are various materials applied for their production. For many decades before and nowadays, the core material for waterthroughput pipes is reinforced concrete. However, there are several reasons that lead to defects and damages of forced and corrosive character bringing those to pre-emergency and emergency states. Among them:

1) Reinforced concrete water-throughput pipes in use are often exposed to joint influence of loading (power influences), and hostile environment (environmental influences).

2) Insufficient attention is paid to a problem of effective operation of reinforced concrete constructions on automobile roads $[22,25]$.

As a result, integrity of an overlying soil embankment is broken, the roadbed collapses and regular traffic on the road is interrupted. One of disadvantages of reinforced concrete constructions is complexity of their strengthening and repair, especially if the purpose of repair is to increase loading capacity of a construction $[15,18]$.

Lately, a special attention is given to a problem of design and calculation of water-throughput pipes considering their factual conditions of exploitation. Especially interesting are findings of Ivanov A.V., Ovchinnikova I.G., Belyaev V. S., Yakovlev L.S., Kalinovsky M. I., Migunov V. N., Petrov E.N., etc. $[3,5,12]$.

Due to a considerable reduction of durability of reinforced concrete water-throughput pipes in aggressive service conditions, a question of how to increase durability of such constructions arises. $[24,27]$

The most effective way to increase durability of water-throughput pipes, according to a number of researchers, is an employment of corrugated steel while producing water-throughput pipes. [6,8]

The main advantages of SCC:

- Small weight of constructions elements;

- Simplicity of assembly; smaller, in comparison with reinforced concrete designs;

- Construction time;

- Attractive appearance;

- The cost of building constructions from corrugated steel is substantially lower than the cost of the small and average bridge constructions with a similar scope $[1,2,19]$. 


\section{Description of research}

During an assessment of this experiment, the following objectives are achieved (Figure 1,2):

1. Comparison of experimental and calculated data of SCC

2. Determination of accuracy and specifications of SCC calculation in intended model of the Method of Finite Elements.

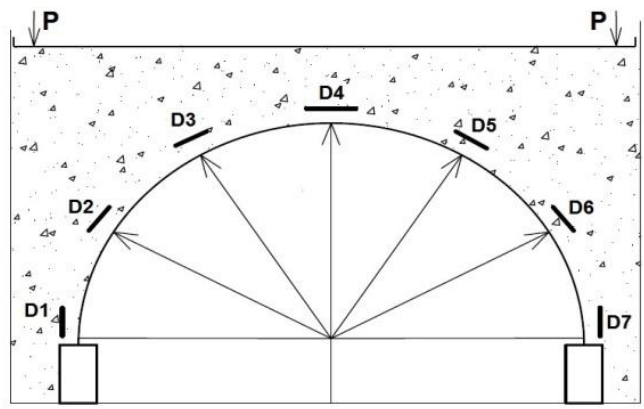

Figure 1. Tests of a semi-circular arch steel corrugated construction.

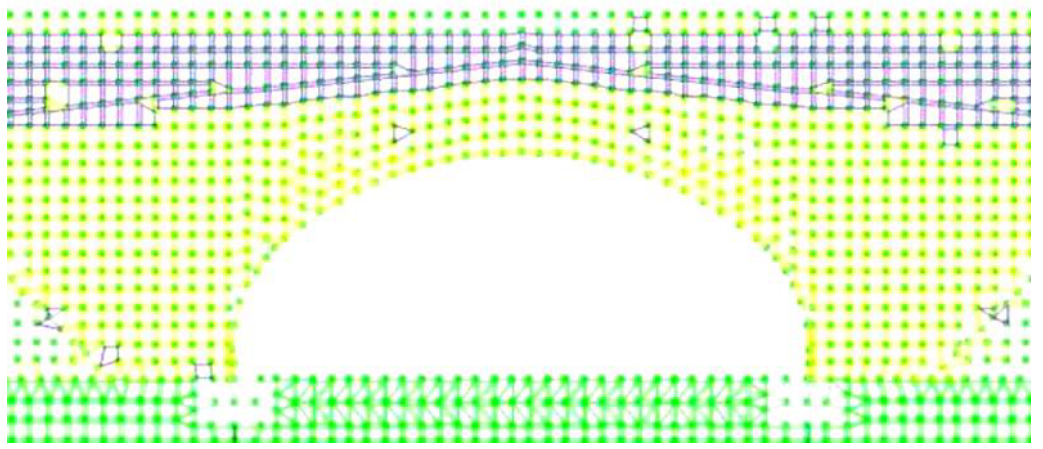

Figure 2. SCC design model.

Object of the current research is an arch SCC of a circular outline with a corner of circular sector $\varphi=90^{\circ}$ (a semi-circular arch). SCC built with corrugated sheets by a profile of $381 \times 140 \mathrm{~mm}, 7 \mathrm{~mm}$ thick. Tests were carried out in the camera of volume loading, the sizes $8.0 \times 4.5 \times 3.5$ of $\mathrm{m}$ having one mobile wall. Movement of a mobile wall was carried out by means of the battery of the hydro jacks having total effort 2700 t.f. and the course of rods to $1.0 \mathrm{~m}$ of SCC I was in the camera of volume loading in horizontal position. Fixing of heels of arch SCC-hinged. The distance between walls of the camera and SCC was filled with coarse-grained sand with layer-by-layer consolidation.

In total 28 sensors, including 7 sensors of soil pressure, 14 sensors of relative deformations (gage), 7 sensors of deflections were installed. All sensors of deformations are focused along the corrugation. In Fig. 1 are shown the installed sensors of relative deformations and the sensor of relative movements in the SCC model.

The layer-by-layer filling with sandy soil in space between walls of the load camera and SCC was carried out, and the necessary height of a filling of $2.6 \mathrm{~m}$ was reached by laying of eight layers of soil on $0.25-0.35 \mathrm{~m}$.

Tests were completed at the appendix of the mobile wall of loading distributed on all area which size is determined by indications. Indications specified were averaged and transferred to the height of a column of conditional soil with the specific weight of $20000 \mathrm{~N} / \mathrm{m}^{3}[1,2,3]$. 
Table 1. Values of intensity of equivalent loading of SCC

\begin{tabular}{|c|c|}
\hline$q[\mathrm{kN} / \mathrm{m}]$ & Height of a conditional filling $[\mathrm{m}]$ \\
\hline 467 & 30 \\
\hline
\end{tabular}

Table 2. Value of the characteristic of materials

\begin{tabular}{|l|c|c|}
\hline \multicolumn{1}{|c|}{ Name } & Soil & Steel \\
\hline Module of elasticity [MPa] & 22.2 & $2 * 10^{6}$ \\
\hline Poisson's coefficient & 0.3 & 0.3 \\
\hline Density $\left[\mathrm{Kg} / \mathrm{m}^{3}\right]$ & 1700 & 7800 \\
\hline Calculated resistance on strength $[\mathrm{MPa}]$ & - & 300 \\
\hline Coupling coefficient & 0.005 & - \\
\hline Corner of internal friction & 37 & - \\
\hline
\end{tabular}

Results of test and comparison of experimental data with calculated (Figure 3-5, Table 3):

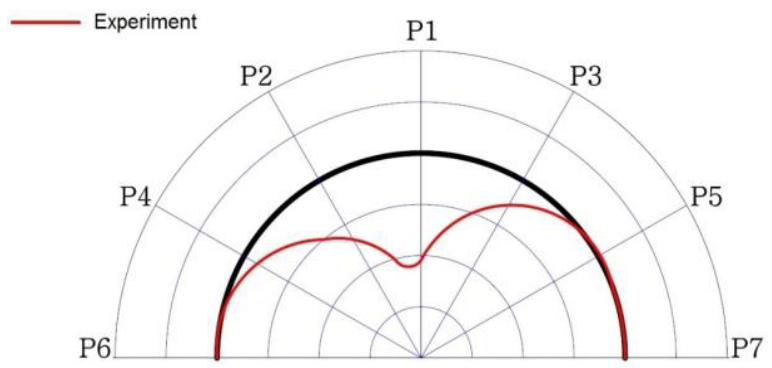

Figure 3. An experimental form of deformation of SCC (1 radial division $-50 \mathrm{~mm})$

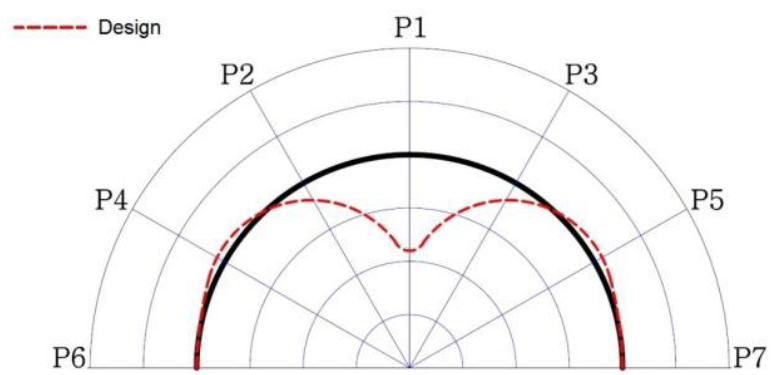

Figure 4. Design form of deformations of SCC

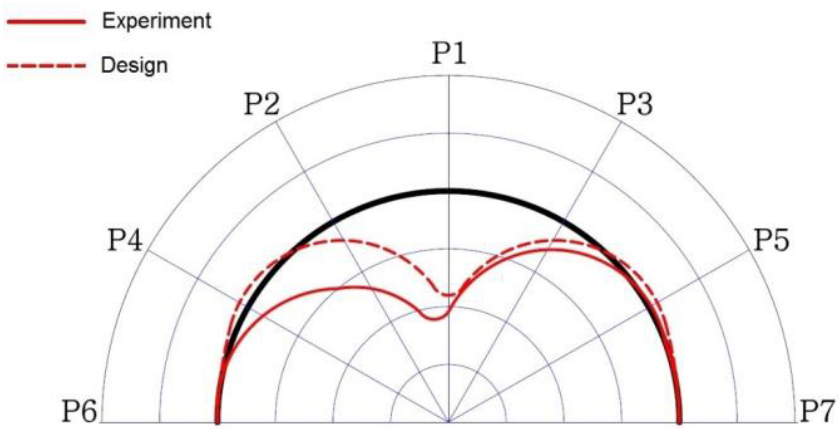

Figure 5. Experimental and design form of deformation of SCC 
Table 3. Comparison of results of the experiment

\begin{tabular}{|c|c|c|c|c|c|c|c|c|c|}
\hline \multirow{2}{*}{$\begin{array}{l}\text { Method of } \\
\text { determinati } \\
\text { on of } \\
\text { tension }\end{array}$} & \multirow{2}{*}{$\begin{array}{c}\text { Location of } \\
\text { sensors }\end{array}$} & \multicolumn{7}{|c|}{ Values of normal tension [MPa] } & \multirow{2}{*}{ 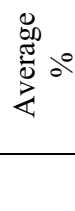 } \\
\hline & & $\mathrm{t} 11-12$ & t7-8 & t3-4 & $\mathrm{t} 1-2$ & t5-6 & t9-10 & t13-14 & \\
\hline Experiment & \multirow[b]{2}{*}{ Corrugation top } & +169 & +147 & -400 & -609 & +298 & +209 & +158 & \\
\hline $\begin{array}{l}\text { Method of } \\
\text { finite } \\
\text { elements }\end{array}$ & & -103 & +67 & -314 & -300 & -314 & +67 & -103 & \\
\hline Accuracy & $\%$ & 39 & 54 & 22 & 51 & -5 & 68 & 35 & 38 \\
\hline Experiment & \multirow[b]{2}{*}{$\begin{array}{c}\text { Corrugation } \\
\text { hollow }\end{array}$} & -512 & -538 & -58 & +806 & -262 & -542 & -557 & \\
\hline $\begin{array}{l}\text { Method of } \\
\text { finite } \\
\text { elements }\end{array}$ & & -185 & -318 & +146 & +268 & +146 & -318 & -185 & \\
\hline Accuracy & $\%$ & 64 & 41 & 15 & 67 & 44 & 41 & 67 & 48 \\
\hline
\end{tabular}

\section{Conclusion}

Results of test and comparison of experimental data with design are shown in Fig. 3-5.

Therefore, evaluating factual and calculated results it is possible to draw the following conclusion:

1. Accuracy of calculations for a method of finite elements corresponds $40-50 \%$, from experimental data.

2. In calculated model, there is no input of a possibility of asymmetrical behavior, and actual data demonstrates asymmetrical behavior of corrugated constructions as visible in fig. 3 .

3. Considering it, it is crucial to recommend insuring uniformity of soil of the filling, identical and symmetric level of its merging over a structure while building actual SCC filled with soil, in order to exclude or to reduce probability of occurrence of an asymmetrical nature of deformations in constructions.

In any way, the constructions completed from steel corrugated sheets retain high reliability and possess operational qualities while loaded surpassing calculated ones by 2.5 times.

\section{References}

1. A.V. Ivanov, I.G. Ovchinnikov, Regional'naya arkhitektura i stroitel'stvo, 1(2), 43-52 (2007)

2. I.I. Ovchinnikov, M.I. Kalinovskiy, Dorogi i mosty, Sbornik statey FGUP Rosdor 22(2), 186-200 (2009)

3. M.I. Kalinovskiy, I.I. Ovchinnikov, Stroitel'nyye materialy, 10, $15-17$ (2010)

4. I.I. Ovchinnikov, V.N. Migunov, I.G. Ovchinnikov, Zhilishchnoye stroitel'stvo, 10, 6-8 (2012)

5. V.S. Belyayev, L. S. Yakovlev, I.G. Ovchinnikov, I. A. Osokin, Naukovedeniye, 6 (2013)

6. Osokin, I.A., A.S. Permikin, NTU (2012)

7. A.C. Mak, R.W.I. Brachman, I.D. Moore, Washington D.C, 9, 14.

8. D. Beben, The Baltic journal of road and bridge engineering, 4 (1), 13-21 (2009)

9. N. Vatin, J. Havula, L. Martikainen, A. S. Sinelnikov, A. Orlova, S. Salamakhin Advanced Materials Research, 945-949, 1211-1215 (2014)

10. I.G. Ovchinnikov, Naukovedeniye, 6 (2013)

11. V. Lalin, V. Rybakov, A. Sergey, Applied Mechanics and Materials, 578-579, 858-863 (2014) 
12. Y. Lazarev, G. Sobko, M. Chakir, Applied Mechanics and Materials, 584-586, 1681-1686 (2014)

13. N.I. Vatin, O. Gamayunova, Applied Mechanics and Materials, 670-671, 1612-1615 (2014)

14. V. Rybakov, A. Panteleev, G. Sharbabchev, E. Epshtein, Applied Mechanics and Materials, 584586, 1876-1880 (2014)

15. N. Vatin, J. Havula, L. Martikainen, A. Sinelnikov, L. L. Shurovkina, Applied Mechanics and Materials, 725-726, 722-727 (2015)

16. D. Trubina, D. Abdulaev, E. Pichugin, V. Rybakov, Applied Mechanics and Materials, 633-634, 1133-1139 (2014)

17. M. Garifullin, D. Trubina, N. Vatin, Applied Mechanics and Materials, 725-726, 697-702 (2015)

18. M. Seslija, N. Radovic, N. Vatin, Applied Mechanics and Materials, 725-726, 596-604 (2015)

19. Y.G. Lazarev, SPbGASU, 93 (2013)

20. Y.G. Lazarev, Y.B. Sinitsyna, Tekhniko-tekhnologicheskiye problemy servisa, 2(24), 92-93, (2013)

21. N. Vatin, A. Sinelnikov, M. Garifullin, D. Trubina, Applied Mechanics and Materials 633-634, 1037-1041 (2014)

22. V.N. Bukhartsev, M.R. Petrichenko, Power Technology and Engineering, vol.44, 5, 374-377 (2012)

23. M.R. Petrichenko, N.S. Kharkov The Russian Journal of Applied Physics, 54 (7), 1063-1065 (2009)

24. V.N. Bukhartsev, M.R. Petrichenko, Power Technology and Engineering, 46,185-189 (2012)

25. V.N. Bukhartsev, M.R. Petrichenko, Power Technology and Engineering, 46(1), 1-3 (2012)

26. M.R. Petrichenko, Heat transfer-Soviet Research, 23(5), 703-714 (1991)

27. N. Vatin, J. Havula, L. Martikainen, A. Sinelnikov, L.L. Shurovkina, Applied Mechanics and Materials, 725-726, 722-727 (2015)

28. F. Peterson, R. Fruchter, M. Fisher, T. Hartmann, Automation on construction, 20 (2), 115-125 (2011)

29. M. V. Ananina, N. A. Beresneva, L. L. Shurovkina, Construction of Unique Buildings and Structures, 7 (22), 54-70 (2014)

30. N. Vatin, A. Sinelnikov, M. Garifullin, D. Trubina, Applied Mechanics and Materials, 633-634, 1037-1041 (2014) 